\title{
Recycling of electrolytic manganese solid waste in autoclaved bricks preparation in China
}

\author{
Bing Du $\cdot$ Chang-bo Zhou $\cdot$ Ning Duan
}

Received: 4 December 2012/Accepted: 28 July 2013/Published online: 22 August 2013

(C) Springer Japan 2013

\begin{abstract}
China has played a dominant role in global electrolytic manganese metal (EMM) production, accounting for over $98 \%$ of the total world capacity since 2008. However, with the rapid development of the EMM industry and depletion of mineral ores, electrolytic manganese solid waste (EMSW) is piling up, so more largescale landfills are needed. The environmental problems generated by EMSW pose severe threats to soil and ground water, and have become the hot issues in society. The aim is to consume and recycle EMSW, and the primary route is to make autoclaved bricks. However, less attention has been given to the procedure and strength-forming mechanism of EMSW bricks, not to mention the production line of the brick. On the basis of physical and chemical property analysis, the pretreatment process of EMSW was indispensable to solidify/stabilize the heavy metals, such as Mn, $\mathrm{Zn}, \mathrm{Cd}, \mathrm{Pb}$, etc.. This paper expatiated on the procedure of making EMSW autoclaved bricks, analyzed in detail the
\end{abstract}

\section{B. Du $(\bowtie)$}

State Key Laboratory of Environmental Aquatic Chemistry, Research Center for Eco-Environmental Sciences, Chinese Academy of Sciences, 18 Shuangqing Road, Haidian District, Beijing 100085, China

e-mail: w.dubing@gmail.com

\section{Zhou}

Cleaner Production Centre, Chinese Research Academy of Environmental Sciences, 8 Beiyuan Road, Chaoyang District, Beijing 100012, China

e-mail: zhoucb@craes.org.cn

\section{N. Duan}

Technology Center for Heavy Metal Cleaner Production Engineering, Chinese Research Academy of Environmental Sciences, 8 Beiyuan Road, Chaoyang District,

Beijing 100012, China

e-mail: ningduan@craes.org.cn strength formed by different cementitious materials with cement properties, and introduced the practical engineering of EMSW autoclaved bricks. The results showed that the pretreatment process with quicklime was effective in solidifying/stabilizing the heavy metals. The compressive strength of EMSW bricks reached $10.05 \mathrm{MPa}$ when quicklime $9 \%(\mathrm{w} / \mathrm{w})$ added. Cement may be an ideal cementitious material to create EMSW bricks of high strength in experiments and on the production line. Quicklime and cement used simultaneously produced a lower strength than that when adding cement alone because the gypsum from EMSW and an alkali could generate deleterious effects, e.g., expansion or burst. In the production line of EMSW bricks, an appropriate mix proportion to make high-quality autoclaved bricks was determined: EMSW 30-40\%, cement 10-20\%, and aggregates $40-60 \%$. The low content of heavy metals tested by toxicity leaching may deduce that the EMSW autoclaved bricks have low environmental risk. However, long-term environmental risk evaluation will be needed, requiring more tests and leaching modeling. Employing EMSW to make high-quality autoclaved bricks may be a promising waste-to-resource strategy.

Keywords Electrolytic metal manganese (EMM) . Electrolytic manganese solid waste (EMSW) .

Autoclaved brick . Strength mechanism .

Pretreatment

\section{Introduction}

The electrolytic metal manganese (EMM) industry has developed at a dramatic pace since 2000. More than 200 companies have boomed in this industry, bringing 
approximate 20 billion tons of EMM every year. Up to 2010, the production capability had exceeded $2 \mathrm{Mt} / \mathrm{a}$, accounting for $98 \%$ of the total capability of the total worldwide annual production [1]. At present, China has become the biggest country worldwide producing, consuming, and exporting EMM. Particularly, the stainless steel 200 series is replacing traditional nickel-containing stainless steel, thus, promoting the development of the EMM industry.

The EMM industry as a whole is generally defined as an industry with a high level of resource consumption and large amounts of discharged solid waste [2]. The EMM process is a traditional hydrometallurgical process, described briefly as follows: (a) sulfuric acid leaching; (b) iron removal by oxidation; (c) heavy metals removal; (d) electrolysis, which is widely applied in about $95 \%$ of EMM enterprises in China. The main raw ore of EMM production in China is rhodochrosite, which is ubiquitous, with grade below $20 \%$, on average. Electrolytic manganese solid waste (EMSW), not including chromium slag from waste water treatment and anode slime from electrolytic processes, is the residue of solid-liquid separation after the leaching of sulfuric solution. Thus, to produce 1 ton of EMM, 7-9 tons of EMSW are discharged. It was estimated that the amount of EMSW had exceeded 55 million tons by 2008, when the rate of EMSW generation reached 10 million tons/a. The situation has become worse because more land would be devoured.

The chemical composition of EMSW is complicated, containing many toxic and hazardous contaminates $(\mathrm{Pb}$, $\mathrm{Cd}, \mathrm{Cu}, \mathrm{Zn}, \mathrm{Cr}$, etc.) [3]. In addition, material balance analysis of EMM production showed that $13.7 \% \mathrm{Mn}$, $17 \%$ Se, and $44.1 \%$ ammonia nitrogen made up EMSW [2]. It is possible that the contaminant would diffuse into the surrounding soil and ground water through the leachate by rainfall. Therefore, the piling up of EMSW in unlined landfills may pose severe threats to the eco-environment and health of the local community.

A more appropriate method to reduce the amount of EMSW is recycling as a raw resource. Since the major EMM production plants around the world are largely distributed in China and South Africa, the recycling technologies are also developed and applied in both countries. Extensive research has been dedicated to developing beneficial uses of EMSW, including: (a) as a cement retarder instead of (totally or partially) natural gypsum [4]; (b) making fine fertilizer [5, 6]; (c) making roadbed materials [7, 8]; (d) making building bricks [9, 10]; (e) preparing chemical raw materials [11].

By comparison with the recycling methods mentioned above, it was found that the performance of recycling products, such as fertilizer and retarder, satisfy a high level of quality, but their applications are subject to low value addition $(<5 \% \mathrm{~m} / \mathrm{m})$, high cost and complex processes. However, the approach of making bricks may be more feasible than those approaches in practice because of the advantage of cheap raw materials, simple processes, and easy operations. Note that autoclaved bricks may be suitable for recycling EMSW due to its ripe process, reliable application, and wide acceptance in waste deposal. Wang [12] prepared autoclaved bricks utilizing EMSW mixed with cement and mountain sand. However, the toxicity characteristic test of the bricks showed that the $\mathrm{Pb}$ concentration far beyond the regulatory limits of $1.0 \mathrm{mg} / \mathrm{L}$ for $\mathrm{Pb}$. The Manganese Metal Company (MMC) of South Africa used EMSW to make clinker bricks and the results showed that, although the standard bricks $(230 \times$ $113 \times 65 \mathrm{~mm})$ satisfied the requirements of building materials, tawny stains would appear on the wall during the service time of the brick. Hence, there are some technological barriers in making EMSW autoclaved bricks. The strength mechanism of EMSW autoclaved bricks has never been investigated and the industrial production of the bricks has also never been reported previously. Thus, it is meaningful to conduct such research.

The objective of this study was to elucidate the strength mechanism of the EMSW autoclaved bricks prepared by different compositions and parameters. For this study, the physical and chemical properties and environmental characteristics of EMSW is first presented. Based on those results and experimental achievements, the first production line of EMSW autoclaved bricks was established in Guizhou, China. A combination of theoretical analysis and practical engineering will improve the waste disposal capacity and promote the integration of production, teaching, and research in waste recycling.

\section{Materials and methods}

\section{Materials}

\section{EMSW}

EMSW was obtained from Tianxiong Electrolytic Manganese Co., Ltd. in Chongqing. Each sample of approximately $500 \mathrm{~g}$ was collected from four different corner spots of each filter cake for 7 continuous days after 30 days of normal continuous production. Sealing the sample was done in order to preserve them in their original state. Then, they were desiccated at $60{ }^{\circ} \mathrm{C}$ and mixed together. The physical and chemical properties are shown in Table 1.

The X-ray diffraction (XRD) diffractogram of EMSW depicted in Fig. 1 shows that there is an appreciable amount of crystalline materials, predominantly gypsum $\left(\mathrm{CaSO}_{4} \cdot 2 \mathrm{H}_{2} \mathrm{O}\right)$ and quartz $\left(\mathrm{SiO}_{2}\right)$. Amorphous materials are 
Table 1 Physical and chemical properties of electrolytic manganese solid waste (EMSW)

\begin{tabular}{ll}
\hline $\mathrm{pH}_{\mathrm{H} 2 \mathrm{O}}$ (liquid-to-solid of 5) & $6.1 \pm 0.2$ \\
Bulk density $\left(\mathrm{kg} / \mathrm{m}^{3}\right)$ & 1.02 \\
Density $\left(\mathrm{kg} / \mathrm{m}^{3}\right)$ & 2.64 \\
Specific surface area $\left(\mathrm{m}^{2} / \mathrm{g}\right)$ & 9.655 \\
Average size $($ wet $)(\mu \mathrm{m})$ & 44 \\
$\mathrm{Moisture} \mathrm{content}(\%)^{{ }^{1}(\leq 1.0)}$ & 29.6 \\
$\mathrm{IRa}^{1}(\leq 1.0)$ & 0.2 \\
$\mathrm{Ir}^{1}(\mathrm{mg} / \mathrm{kg})$ & 0.5 \\
$\mathrm{~S}_{\mathrm{x}}(\mathrm{mg} / \mathrm{kg})$ & $7.96 \pm 0.08$ \\
$\mathrm{Si}$ ( $)$ & $8.03 \pm 0.09$ \\
$\mathrm{Ca}(\mathrm{mg} / \mathrm{kg})$ & $6.33 \pm 0.10$ \\
$\mathrm{Al}(\mathrm{mg} / \mathrm{kg})$ & $2.72 \pm 0.06$ \\
$\mathrm{Mn}(\mathrm{mg} / \mathrm{kg})$ & $2.36 \pm 0.07$ \\
$\mathrm{Zn}(\mathrm{ppm})$ & $7.5 \pm 0.4$ \\
$\mathrm{~Pb}(\mathrm{ppm})$ & $6.9 \pm 0.6$ \\
$\mathrm{Ni}(\mathrm{ppm})$ & $3.9 \pm 0.4$ \\
$\mathrm{Se}(\mathrm{ppm})$ & $2.5 \pm 0.2$ \\
$\mathrm{Cr}(\mathrm{ppm})$ & $2.4 \pm 0.3$ \\
\hline
\end{tabular}

$I R a^{l}$ Internal exposure index, $\operatorname{Ir}^{l}$ External exposure index

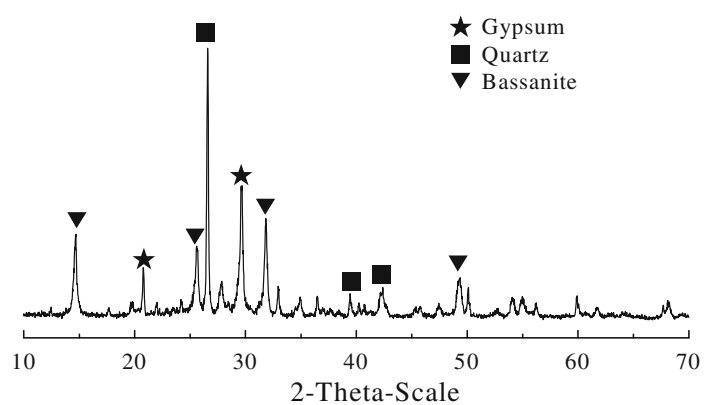

Fig. 1 X-ray diffraction (XRD) diffractogram for electrolytic manganese solid waste (EMSW)

indistinct and it shows that the amount was less than the assumed predictions. The scanning electron microscope (SEM) diagram of EMSW depicted in Fig. 2 shows a great deal of cylindrical granules stacked disorderly and absorbed superfine particles.

The leaching behavior was tested by the toxicity characteristic leaching procedure (TCLP) test, a full description of which has been provided elsewhere [13]. The results of the EMSW before treatment presented in Table 3 show that the concentrations of the metal dissolved, except manganese, are under the threshold values. The concentration of manganese is much higher than the limit value $(\leq 0.1 \mathrm{mg} /$ L) of Class III of the Quality Standard for Ground Water (GB/T 14848-93). Therefore, EMSW cannot be disposed into unlined landfill unless it is treated.

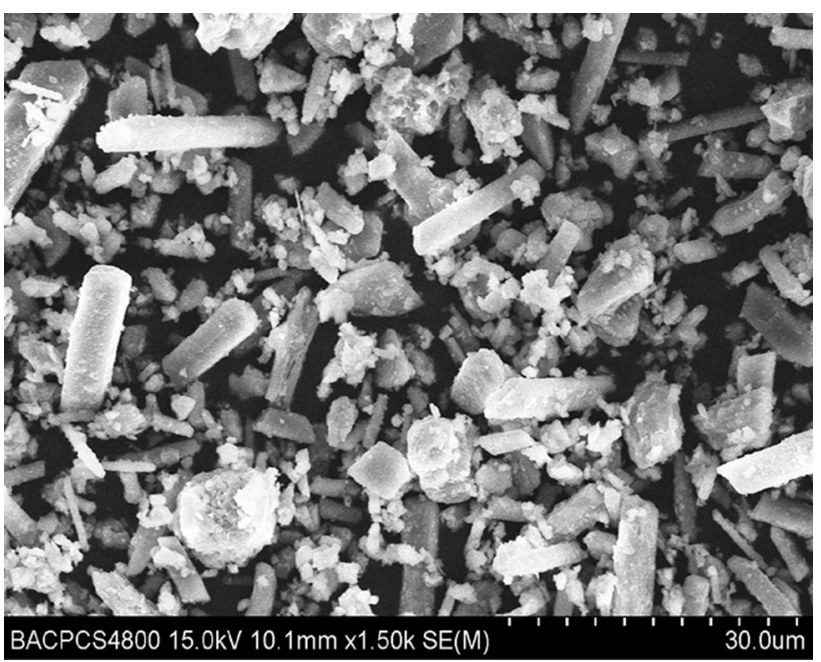

Fig. 2 Scanning electron microscope (SEM) diagram of EMSW

Table 2 Mechanical properties of cement

\begin{tabular}{lll}
\hline $\begin{array}{l}\text { Curing time } \\
\text { (days) }\end{array}$ & $\begin{array}{l}\text { Flexural strength } \\
(\mathrm{MPa})\end{array}$ & $\begin{array}{l}\text { Compressive strength } \\
(\mathrm{MPa})\end{array}$ \\
\hline 3 & 6.5 & 24.4 \\
28 & 9.4 & 46.8 \\
\hline
\end{tabular}

\section{Other materials}

Quicklime with active $\mathrm{CaO} 85 \%$ was used and proportion of material remaining after being passed through a $120-\mu \mathrm{m}$ sieve was less than $5 \%(\mathrm{w} / \mathrm{w})$. An XRD diffractogram of the quicklime shows that the main mineral composition is lime $(\mathrm{CaO})$ [37-1497], calcite $\left(\mathrm{CaCO}_{3}\right)$ [05-0586], and portlandite $\left[\mathrm{Ca}(\mathrm{OH})_{2}\right]$ [04-0733].

The mechanical properties of P.O. 42.5 Portland cement used in the experiments are shown in Table 2. The particle size distribution for Portland cement determined by light scattering showed that the mass fractions of $>40,20-40$, and $<20 \mu \mathrm{m}$ were 15,29 , and $56 \%$, respectively.

Two kinds of aggregate were used, coarse natural sand (size $2.5-5.0 \mathrm{~mm}$ ) and fine natural sand (size $\leq 0.5 \mathrm{~mm}$ ), both of which were altered to have the composition of $\mathrm{SiO}_{2}$ $>90 \%$ and silt content $<0.5 \%$. The details of preparing this kind of aggregate can be found elsewhere [7].

\section{Pretreatment of EMSW}

Before preparing the brick, EMSW must be pretreated for its high concentration of manganese. Heavy alkalinity reagents, such as quicklime, were used to stabilize the contaminants of the hazardous waste, which was effective and verified by other researchers [14]. The formulation of pretreatment was a dose of $120 \mathrm{~g}$ of quicklime added per $\mathrm{kg}$ 
Fig. 3 Preparation of making EMSW autoclaved bricks

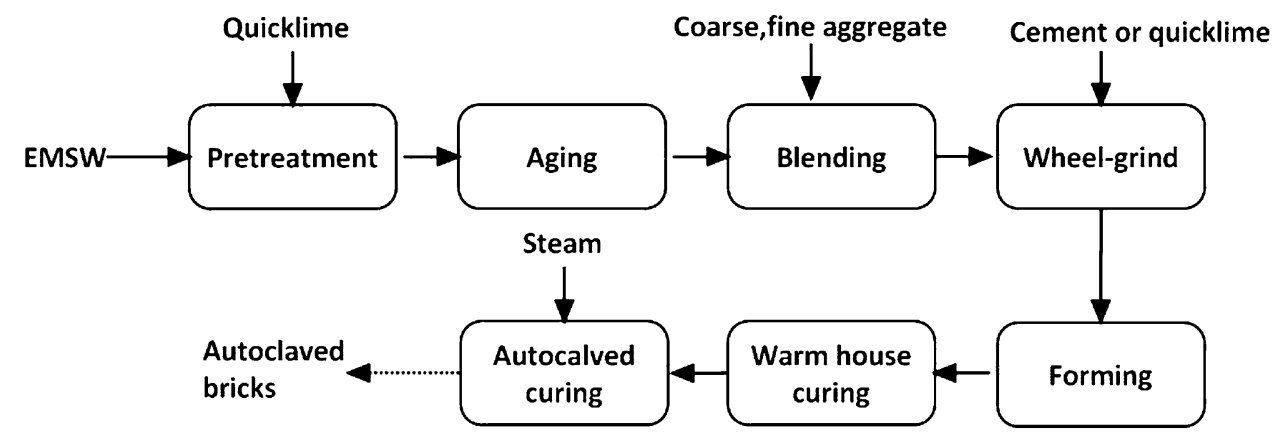

Table 3 Toxicity characteristic test results

\begin{tabular}{|c|c|c|c|c|c|c|c|}
\hline & $\mathrm{Cd}$ & $\mathrm{Pb}$ & $\mathrm{Cr}$ & Mn & $\mathrm{Cu}$ & $\mathrm{Hg}$ & As \\
\hline EMSW before pretreatment & 0.041 & N.D. ${ }^{a}$ & N.D. & 1680 & 0.027 & N.D. & 0.020 \\
\hline EMSW after pretreatment & N.D. & N.D. & N.D. & 0.036 & N.D. & N.D. & N.D. \\
\hline EMSW autoclaved brick & 0.010 & 0.127 & N.D. & N.D. & 0.015 & $4.4 \times 10^{-4}$ & $1.23 \times 10^{-3}$ \\
\hline Limitation of TCLP & 1.0 & 5.0 & 5.0 & $-{ }^{\mathrm{b}}$ & - & 0.2 & 5.0 \\
\hline Limitation of GB 5085.3-2007 & 1.0 & 5.0 & 15 & - & 100 & 0.1 & 5.0 \\
\hline
\end{tabular}

${ }^{a}$ N.D. not detected

b "_" means that there is no threshold value in the standard

of EMSW. Therefore, the pretreatment procedure of EMSW was the addition of quicklime for mixing for $300 \mathrm{~s}$ in a mixer and then dried for more than 5 days. The mixing water at a liquid to solid $(\mathrm{L} / \mathrm{S})$ ratio of 0.2 was used. The pretreated sample was subsampled for the TCLP test and the results are presented in Table 3.

\section{Preparation of EMSW autoclaved bricks}

In this study, an experimental laboratory-scale preparation was selected to ensure that the materials could be well distributed. Pretreated EMSW, aggregates, cement, or quicklime were mixed to form cementing material and then molded into samples with dimension $240 \times$ $115 \times 53 \mathrm{~mm}$ and cured in a warm house for $2 \mathrm{~h}$. Thirtysix bricks were produced in a batch by a ZY1200 hydraulic forming machine. The samples were then placed into an autoclave with a curing regime determined to be 2-6-3 The digits stand for the number of hours at different stages, i.e., temperature increase stage for $2 \mathrm{~h}$, holding stage for $6 \mathrm{~h}$, and decrease stage for $3 \mathrm{~h}$ ) [15]. The preparation process of making EMSW bricks is shown in Fig. 3.

In this study, the water to cement ratio (W:C), steam pressure, and autoclaving time were first determined. Eighteen different compositions of brick specimens were prepared under the conditions given in Table 4. The mixing composition of quicklime, cement, quicklime plus cement,
EMSW, and forming pressure were investigated because those factors were critical for practical engineering purposes.

\section{Strength measurement}

After a curing period of 28 days, the compressive strength of EMSW autoclaved bricks was tested in a NYL-600 test machine and the bending strength was tested in a TYE-10 flexural test device. According to GB 2542-03, five replicates were carried out to determine the mean values. The standard deviations were also calculated.

\section{Microscopic structure analysis}

In order to obtain a view of the microstructure and to conduct a mineral analysis of the hydrated mixture, all samples of EMSW autoclaved bricks were soaked in ethyl alcohol for $48 \mathrm{~h}$ and then desiccated in an oven at $40{ }^{\circ} \mathrm{C}$ to prevent continuous hydration reaction. The dried samples were tested using a JSM-6301F Scanning Electron Microscope (SEM) linked to an energy-dispersive X-ray (EDX) device, which could provide detailed imaging information about the morphology, composition, and surface texture of the brick samples. XRD analyses on specimens were carried out using a Rigaku D/Max-12 kW diffractometer operating at $100 \mathrm{~mA}$ and $40 \mathrm{kV}$, with copper $\mathrm{K}_{\alpha}$ radiation from 10 to $70^{\circ} 2 \theta$ per second. 
Table 4 Test parameters of the experiments

\begin{tabular}{|c|c|c|c|c|c|c|c|c|c|}
\hline \multirow[t]{2}{*}{ Code } & \multicolumn{5}{|c|}{ Mix composition (wt \%) } & \multirow{2}{*}{$\begin{array}{l}\text { Forming pressure } \\
(\mathrm{MPa})\end{array}$} & \multirow[t]{2}{*}{$\mathrm{W}: \mathrm{C}$} & \multirow[t]{2}{*}{ Slaking time $(\mathrm{h})$} & \multirow[t]{2}{*}{ Brick number } \\
\hline & EMSW & Quicklime & Cement & F.S. ${ }^{a}$ & C.S. ${ }^{b}$ & & & & \\
\hline $\mathrm{T} 1$ & 30 & 6 & - & 59 & 5 & 25 & 0.4 & 2 & 36 \\
\hline $\mathrm{T} 2$ & 30 & 9 & - & 56 & 5 & 25 & 0.4 & 2 & 36 \\
\hline $\mathrm{T} 3$ & 30 & 12 & - & 53 & 5 & 25 & 0.4 & 2 & 36 \\
\hline $\mathrm{T} 4$ & 30 & 15 & - & 50 & 5 & 25 & 0.4 & 2 & 36 \\
\hline $\mathrm{T} 5$ & 30 & - & 6 & 59 & 5 & 25 & 0.4 & - & 72 \\
\hline T6 & 30 & - & 7.5 & 57.5 & 5 & 25 & 0.4 & - & 72 \\
\hline $\mathrm{T} 7$ & 30 & - & 9 & 56 & 5 & 25 & 0.4 & - & 72 \\
\hline $\mathrm{T} 8$ & 30 & - & 10.5 & 54.5 & 5 & 25 & 0.4 & - & 72 \\
\hline T9 & 30 & - & 12 & 53 & 5 & 25 & 0.4 & - & 72 \\
\hline $\mathrm{T} 10$ & 30 & 8 & - & 57 & 5 & 25 & 0.4 & 2 & 36 \\
\hline $\mathrm{T} 11$ & 30 & 10 & - & 55 & 5 & 25 & 0.4 & 2 & 36 \\
\hline $\mathrm{T} 12$ & 30 & - & 8 & 57 & 5 & 25 & 0.4 & 2 & 36 \\
\hline $\mathrm{T} 13$ & 30 & - & 10 & 55 & 5 & 25 & 0.4 & 2 & 36 \\
\hline $\mathrm{T} 14$ & 30 & 6 & 10 & 49 & 5 & 25 & 0.4 & 2 & 36 \\
\hline T15 & 30 & 8 & 8 & 49 & 5 & 25 & 0.4 & 2 & 36 \\
\hline T16 & 30 & 10 & 6 & 49 & 5 & 25 & 0.4 & 2 & 36 \\
\hline T17 & 40 & 10.5 & - & 44.5 & 5 & 25 & 0.4 & - & 72 \\
\hline T18 & 50 & 10.5 & - & 34.5 & 5 & 25 & 0.4 & - & 72 \\
\hline T19 & 60 & 10.5 & - & 24.5 & 5 & 25 & 0.4 & - & 72 \\
\hline $\mathrm{T} 20$ & 30 & - & 6 & 59 & 5 & 15 & 0.4 & - & 72 \\
\hline $\mathrm{T} 21$ & 30 & - & 6 & 59 & 5 & 25 & 0.4 & - & 72 \\
\hline $\mathrm{T} 22$ & 30 & - & 6 & 59 & 5 & 35 & 0.4 & - & 72 \\
\hline
\end{tabular}

${ }^{\text {a }}$ Fine sand

${ }^{\mathrm{b}}$ Coarse sand

\section{Results and discussion}

Effect of quicklime mixing composition on strength

The specimens T1-T4 in Table 4 were prepared to determine the effect of the quicklime mixing composition on the compressive and bending strengths. The results of the strength tests are shown in Fig. 4. The compressive strength increased from 3.45 to $10.05 \mathrm{MPa}$ and the bending strength increased from 1.70 to $2.39 \mathrm{MPa}$ by the increasing the composition from 6 to $9 \%$. The highest compressive and bending strengths were obtained with a $9 \%$ quicklime mixing composition. Both the compressive and bending strengths decreased gradually to 2.2 and $0.6 \mathrm{MPa}$, respectively, with the increase of the quicklime composition to $15 \%$. It is evident that there was a threshold value in increasing the strength by using a higher composition of quicklime, above which there was an adverse effect on the strength. The same conclusion was obtained by other researchers [16].

SEM and EDX analyses were conducted on the actual brick samples in order to relate the hydration action between EMSW and other materials with strength

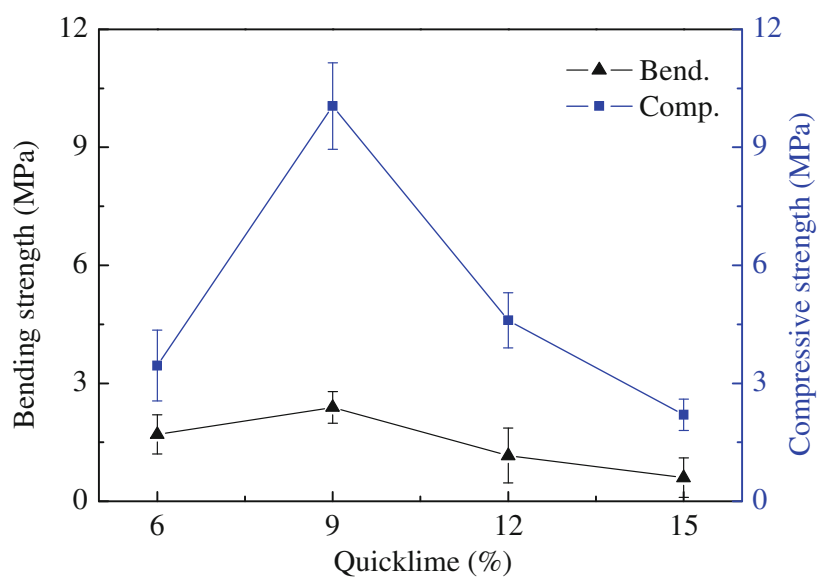

Fig. 4 The effect of the quicklime mixing composition on the compressive and bending strengths

enhancement. Figures 5, 6, and 7 illustrate the SEM imaging information and EDX spectra for the T2 bricks made with EMSW $30 \%$, quicklime $9 \%$, and sand $61 \%$. The images show that a great deal of needle-shaped substances were formed on the surface of the brick sample. Surface hydration and the formation of coatings on 


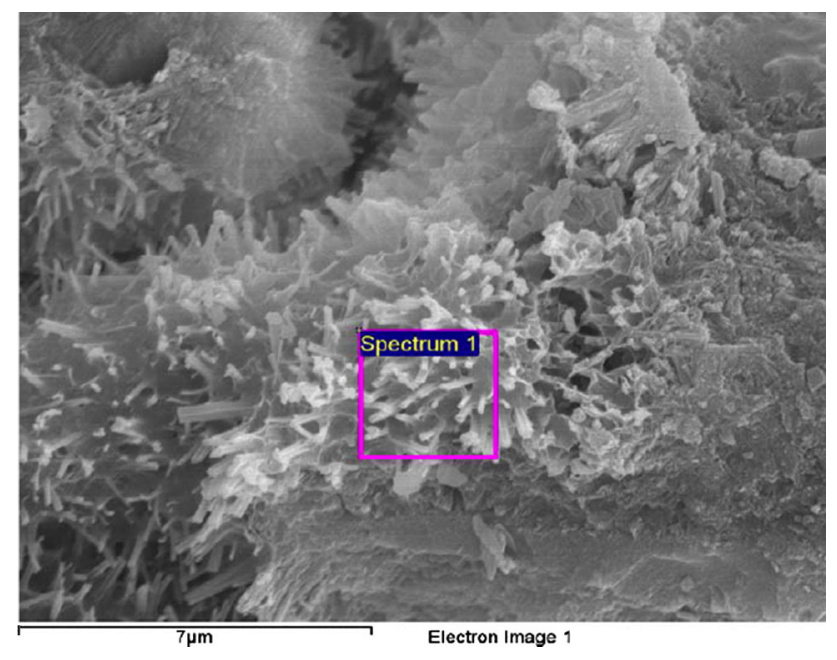

Fig. 5 SEM image of T2 brick

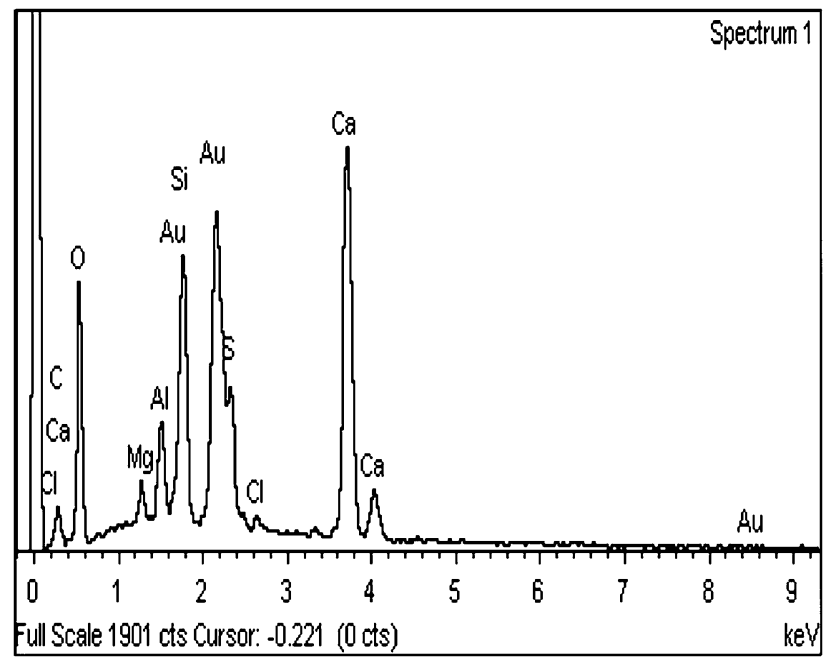

Fig. 6 Energy-dispersive X-ray (EDX) spectrum of T2 brick

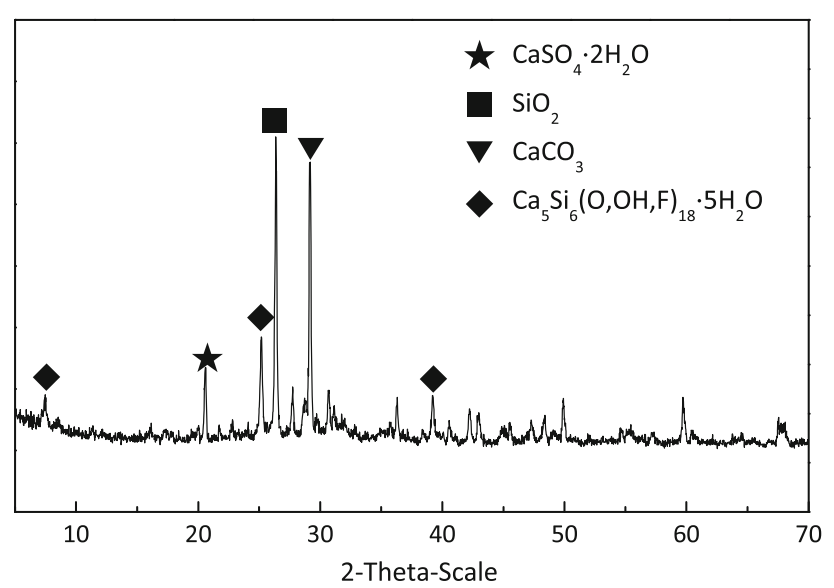

Fig. 7 XRD diffractogram of T2 brick hydration products, due to the high exothermic action of quicklime, are well known [17]. In this case, we could extrapolate the fibrous shape or rod-like substances as $\mathrm{C}-\mathrm{S}-\mathrm{H}$ gel. The elemental analysis of the reaction products for these samples was obtained using the EDX system. The EDX analysis showed that the most prominent elements in the scanning area were observed to be $\mathrm{O}, \mathrm{Ca}$, $\mathrm{Si}$, and $\mathrm{S}$. The sample analyzed by XRD comprised of gypsum $\left(\mathrm{CaSO}_{4} \cdot 2 \mathrm{H}_{2} \mathrm{O}\right)$ [33-0311], quartz $\left(\mathrm{SiO}_{2}\right)$ [461045], calcite $\left(\mathrm{CaCO}_{3}\right)$ [47-1743], and clinotobermorite $\left(\mathrm{Ca}_{5} \mathrm{Si}_{6}(\mathrm{O}, \mathrm{OH}, \mathrm{F})_{18} \cdot 5 \mathrm{H}_{2} \mathrm{O}\right)$ [45-1480]. There is a strong relationship between strength development and corresponding mineralogy, such as pozzolanic product. Clinotobermorite is a typical pozzolanic product whose morphology of normality is nemaline or fibrous, just like the appearance in Fig. 5. In CaO-based systems, the addition of $\mathrm{CaO}$ was sensitive to the presence of pozzolanic products because the persistence of $\mathrm{CaO}$ made their formation slow or nonexistent [18]. In the case of much $\mathrm{CaO}$ added, the system would present with a high $\mathrm{pH}$, which would be detrimental for the transformation of $\mathrm{C}-\mathrm{S}-\mathrm{H}$ gel from strong to weak alkalinity. That the $\mathrm{C}-\mathrm{S}-\mathrm{H}$ gel strength of weak alkalinity is much higher than that of strong alkalinity is well known [19]. Therefore, strength development was significantly compromised with the greater addition of quicklime.

\section{Effect of cement mixing composition on strength}

The results of the compressive strength and bending strength tests conducted on specimens T5-T9 so as to determine the effect of the cement mixing composition are given in Fig. 8. The compressive strength of specimens was increased from 15.6 to $22.1 \mathrm{MPa}$, while the bending strength was increased from 3.47 to $5.80 \mathrm{MPa}$. Higher cement mixing compositions had little significant effects

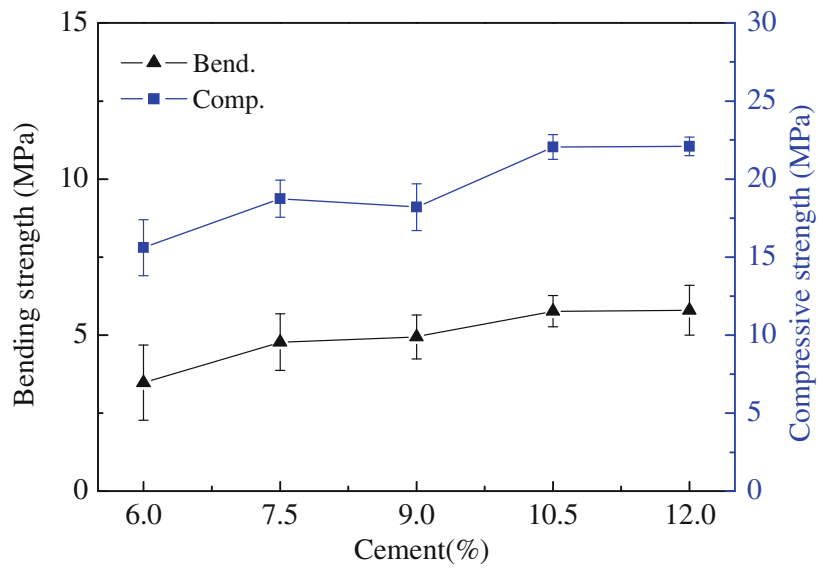

Fig. 8 Effects of the cement addition rate on the compressive and bending strengths 
on the strength increment, since the gradient of the compressive and bending strengths became low when the composition reached $10.5 \%$.

For the T9 system, where pozzolanic action had taken place in binding EMSW and aggregates, the cement played an important role in developing strength. Figures 9, 10, and 11 illustrate the microscopic structure of T9 bricks. It was found in the SEM image that, between the slices segments, there were lots of needle-like gel substances. The most prominent elements in the scanned area were $\mathrm{O}, \mathrm{Ca}$, and $\mathrm{Si}$. According to the XRD analysis, ettringite $\left[\mathrm{Ca}_{6} \mathrm{Al}_{2}\right.$ $\left.\left(\mathrm{SO}_{4}\right)_{3}(\mathrm{OH})_{12} \cdot 26 \mathrm{H}_{2} \mathrm{O}\right]$ formation was clearly identified, especially at $2 \theta$ values of 27.5 and 48.6, the two largest intensity peaks for ettringite location. Several small, difficult-to-discern ettringite peaks suggested that there was minimal pozzolanic product formation. It is known that ettringite is the primary pozzolanic product for strength development in cement matrices. In examining the SEM image of the morphology of ettringite, it was not obvious that the pozzolanic action of cement, perhaps, did not have a complete effect on the morphology. Generally, the reactions between cement and EMSW in water were complex. When the cement reacted with water, the active parts (mainly $\mathrm{C}_{3} \mathrm{~S}$ and $\mathrm{A}_{3} \mathrm{~S}$ ) are soluble on the surface of $\mathrm{SiO}_{2}$, which forms hydration products. Yet, EMSW with a high concentration of $\mathrm{CaSO}_{4} \cdot 2 \mathrm{H}_{2} \mathrm{O}$, the most probable SO2-4 source, may retard the setting of cement. Meanwhile, the SO2-4 in EMSW reacting with cement could lead to the precipitation of $\mathrm{Ca}^{2+}$, which affects the ettringite formation and recrystallization. Additionally, waste particles $<74 \mu \mathrm{m}$ can delay the setting and hardening of cement [20]. The fineness of EMSW affected the setting rate and diffusion of cement into the inter-particle space. Therefore, the strength forming of the cement in autoclaved brick was confined to the EMSW to a certain extent.

Effect of cement and quicklime used simultaneously on compressive strength

To determine the effect of the simultaneous use of cement and quicklime on the compressive strength of EMSW autoclaved bricks, specimens T10-T16 were produced and cured under the same autoclaving regime. The results of the compressive strength tests of these samples are illustrated in Fig. 12. As can be seen, the compressive strength of the bricks using cement and quicklime simultaneously was lower than when using only cement. Besides, under the same addition ( $\mathrm{PC} \%+\mathrm{QL} \%=16 \%)$, the compressive strength increased with the increased addition of the cement and the strength decreased with an increased amount of quicklime. Combined with the previous conclusion, it is apparent that the quicklime adversely reacted to the pozzolanic reaction of the cement.

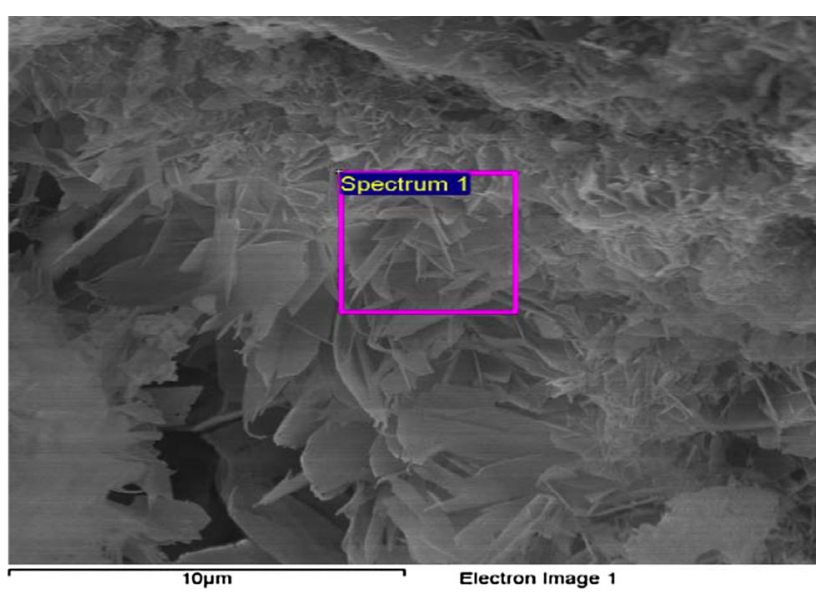

Fig. 9 SEM image of T9 brick

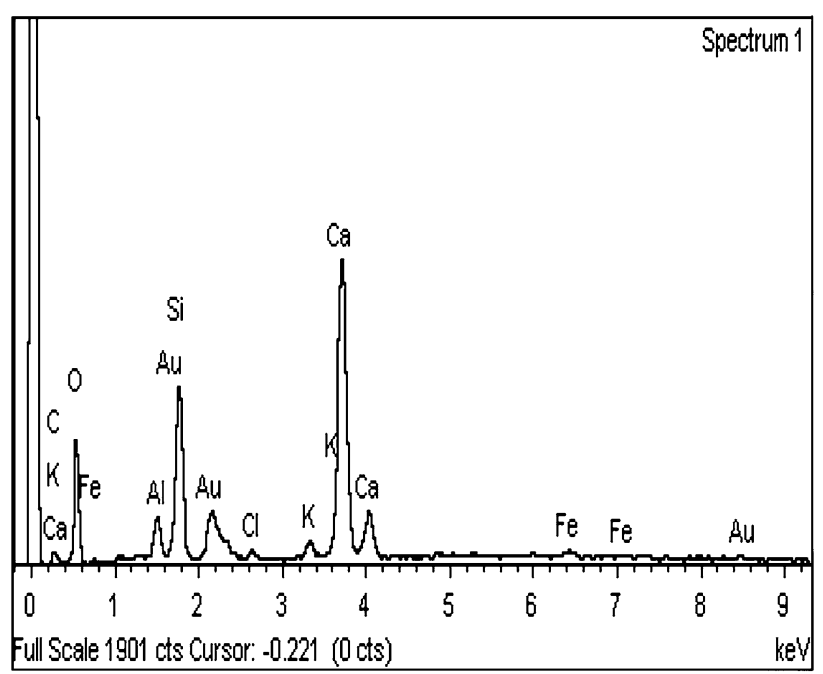

Fig. 10 EDX spectrum of T9 brick

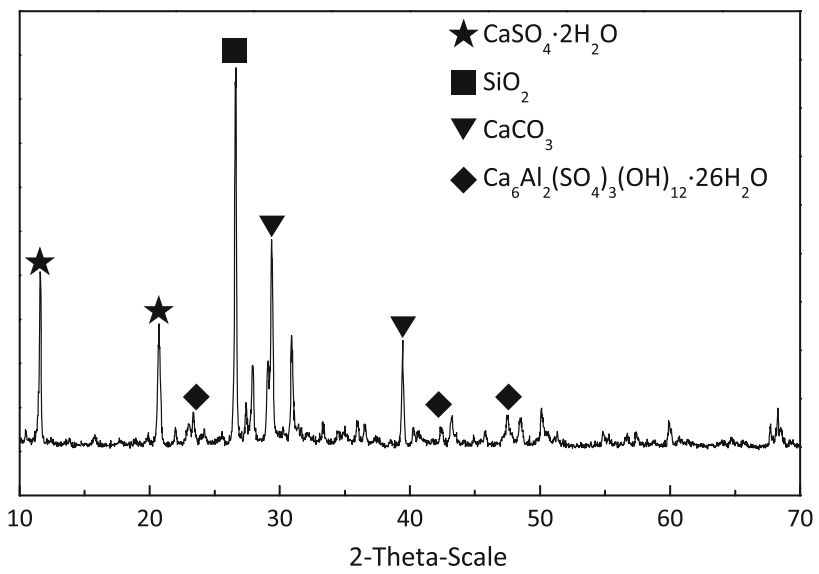

Fig. 11 XRD diffractogram of T9 brick 


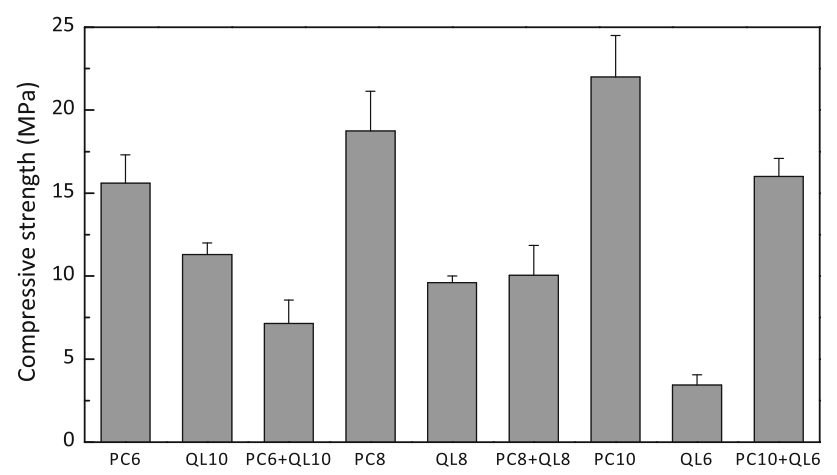

Fig. 12 Comparison of the effects of cement, quicklime, and cement and quicklime used simultaneously on the compressive strength $(P C$ Portland cement, $Q L$ quicklime: the digits indicate the mixing composition)

In this case, with the incorporation of quicklime to constitute a $\mathrm{CaO}-\mathrm{SiO}_{2}$-PC-EMSW system, the cement reacted with $\mathrm{SiO}_{2}$ and $\mathrm{CaSO}_{4} \cdot 2 \mathrm{H}_{2} \mathrm{O}$ to form a complex system. The SEM image of the T15 EMSW brick samples are illustrated in Fig. 13, the EDX spectrum in Fig. 14, and the XRD diffractogram in Fig. 15. The sample comprised of $\mathrm{CaSO}_{4}$ [37-1496], $\mathrm{SiO}_{2}$ [65-0466], and ( $\left.\mathrm{Ca}, \mathrm{Na}\right)(\mathrm{Al},-$ $\mathrm{Si}_{2} \mathrm{Si}_{2} \mathrm{O}_{8}$ [20-0528]. The EDX analysis showed that the most prominent elements in the scanned area were $\mathrm{O}, \mathrm{Ca}$, and $\mathrm{Si}$. As can be seen in Fig. 13, it is possible that the development of the appearance was incomplete and limited, and the quantity of gel was less because the appearance was not easily found, causing the strength to be lower than that formed by using cement alone.

There are two possible reasons for explaining the decrease in strength. First, that calcium sulphate, gypsum $\left(\mathrm{CaSO}_{4} \cdot 2 \mathrm{H}_{2} \mathrm{O}\right)$, or its analogues, such as bassanite $\left(\mathrm{CaSO}_{4} \cdot 0.5 \mathrm{H}_{2} \mathrm{O}\right)$ or anhydrite $\mathrm{CaSO}_{4}$ (including its polymorphic forms $\alpha$ - and $\gamma-\mathrm{CaSO}_{4}$ ), were added as set-controlling agents is well known. Note that destructive expansion from the reaction with sulphate can occur at a high concentration in cement $[21,22]$. In the presence of gypsum from EMSW and an alkali, some phases such as the U-phase $\left[\mathrm{C}_{4} \mathrm{~A}_{0.9}\left(\mathrm{SO}_{4}\right)_{1.1} \mathrm{~N}_{0.5} \mathrm{H}_{16}\right]$ will form and may cause deleterious effects, in particular, causing expansion or burst to reduce the mechanical strength [23]. Second, the cement, due to its faster rate of hydration than quicklime, concreted with particles of EMSW and aggregates to form the early strength of the brick. Assuming acting with $\mathrm{SiO}_{2}$, the quicklime needed firstly to slake to convert Cao to $\mathrm{Ca}(\mathrm{OH})_{2}$. While this conversion occurred, most of the surface of $\mathrm{SiO}_{2}$ in EMSW was likely to be coated by the $\mathrm{AFm}$, which is an earth hydration reaction of cement, causing $\mathrm{Ca}(\mathrm{OH})_{2}$ to fail to contact directly with and $\mathrm{SiO}_{2}$ to form $\mathrm{C}-\mathrm{S}-\mathrm{H}$ gel and high $\mathrm{pH}$ surroundings, which had detrimental effects on the solubility of $\mathrm{Ca}^{2+}, \mathrm{SO} 2-4$, and $\mathrm{Al}(\mathrm{OH})-4$ for ettringite regeneration [24].

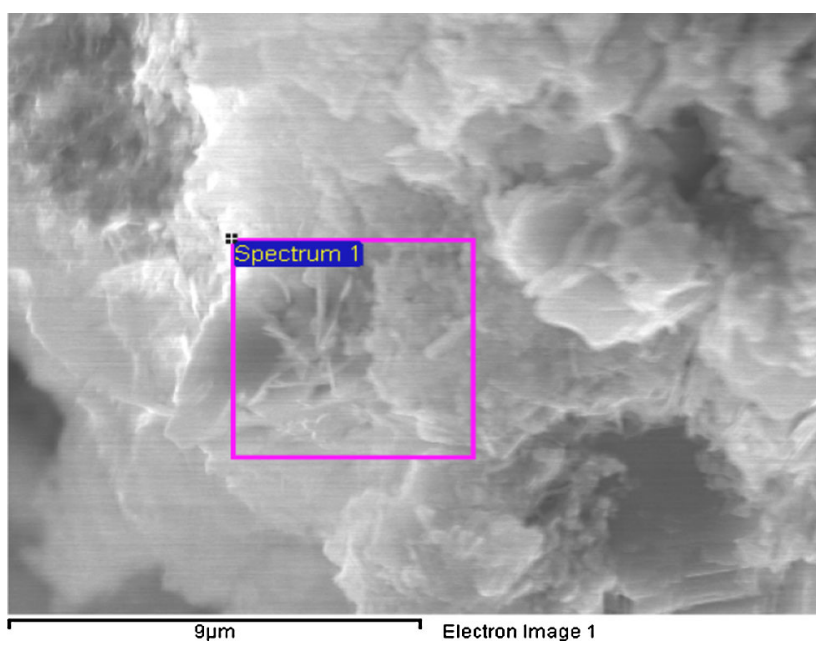

Fig. 13 SEM image of T15 brick

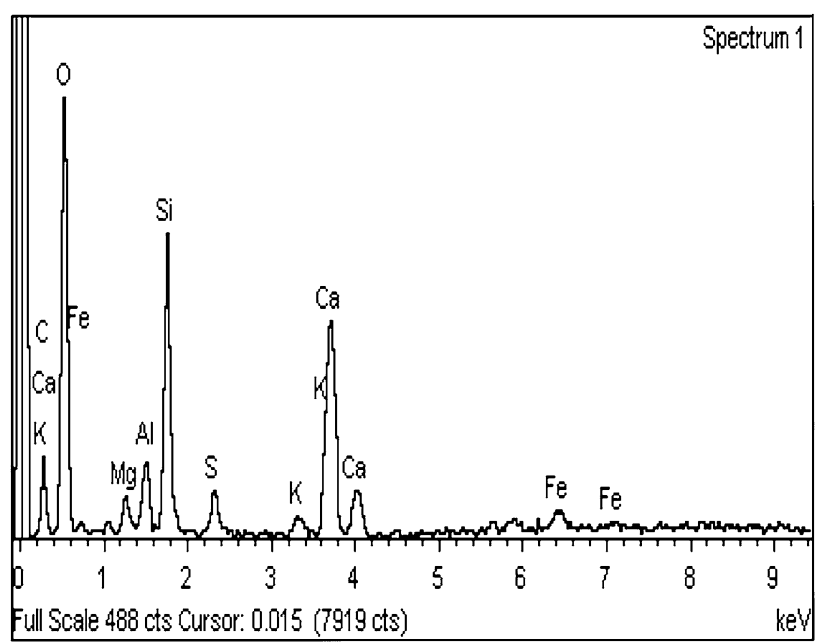

Fig. 14 EDX spectrum of T15 brick

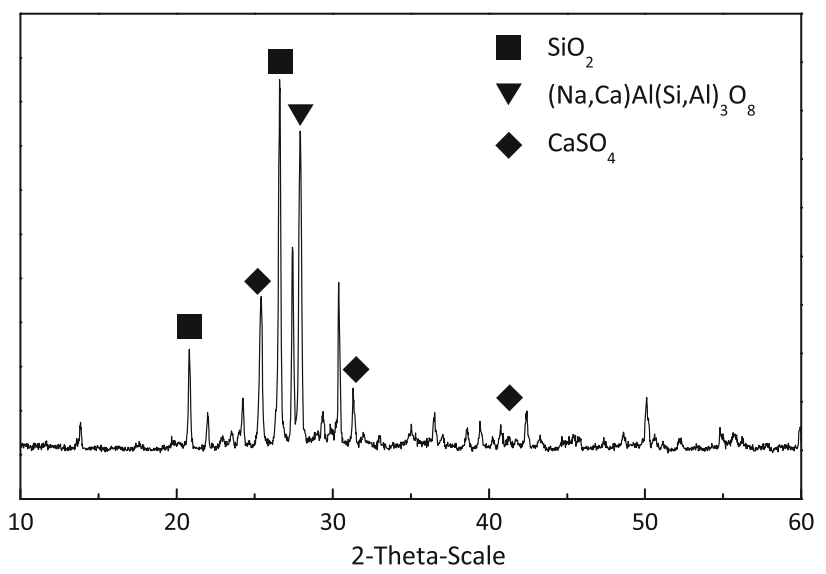

Fig. 15 XRD diffractogram of T15 brick 


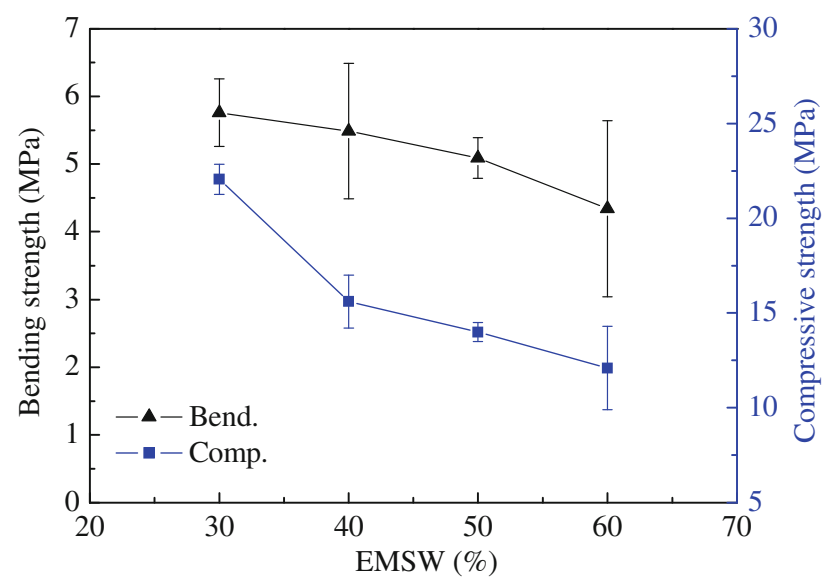

Fig. 16 Effect of EMSW addition on the bending and compressive strengths

Effect of EMSW mixing composition on strength

Higher EMSW mixing compositions with cement have important connotations in the production of EMSW autoclaved bricks, so as to consume EMSW as much as possible to lower the content within cement and counter the environmental effects. Thus, the effect of the EMSW mixing composition on strength was investigated using specimens T8 and T17-T19. The results are illustrated in Fig. 16.

Note that both the compressive and bending strengths decreased gradually with the mixing composition of EMSW addition increasing from 30 to $60 \%$. The compressive strength decreased from 22.05 to $12.10 \mathrm{MPa}$ and the bending strength decreased from 5.76 to $4.34 \mathrm{MPa}$. The loss rates of the compressive and bending strengths were calculated to be 45 and $24 \%$, respectively, which was lower than the loss of strength of autoclaved bricks made by copper tailings [25]. Researches have expatiated that the durability of autoclaved bricks may have a direct relationship with the mechanical strength [26]. The lower loss of strength implied that the EMSW autoclaved bricks could possess good durability to resist the effects of weather. It makes sense to produce load-bearing bricks with ideal mechanical strength.

\section{Effect of forming pressure on strength}

The forming pressure exerted a marked influence on the compressive and bending strengths of the bricks by changing the compactness and, thus, the initial and autoclaved strengths; the products of high initial strength have a low destructive percentage when moved from forming equipment to autoclave [15]. The effect of the forming

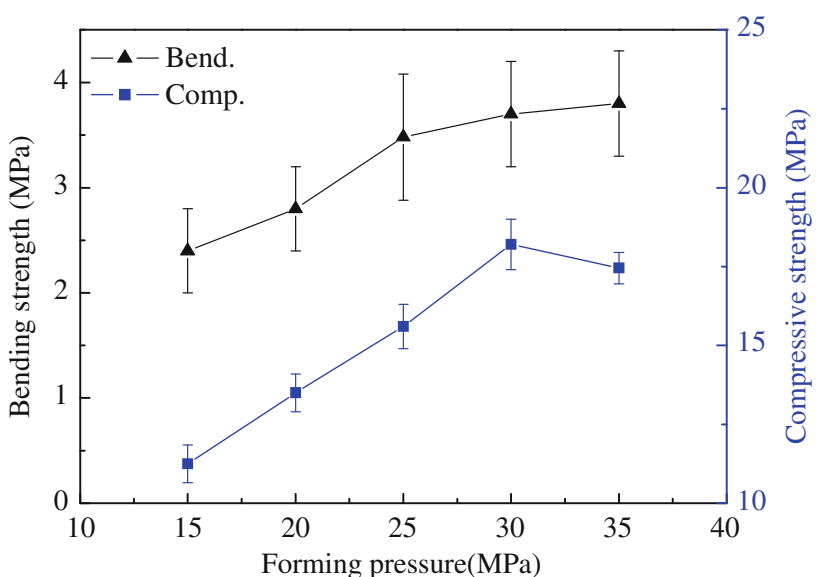

Fig. 17 Effect of forming pressure on the bending and compressive strengths

pressure on the bending and compressive strengths is shown in Fig. 17.

It is clear from Fig. 17 that the bending strength of the EMSW autoclaved bricks was increased from 2.4 to 3.8 MPa with the forming pressure, while the compressive strength was increased until the forming pressure was raised beyond $30 \mathrm{MPa}$. Thus, it is unnecessary to overincrease the forming pressure because a similar conclusion was drawn in a previous study [15]. For one thing, much higher pressures could pose tremendous elastic deformation due to air in the materials being intensively squeezed. Once the forming pressure exceeded the critical forming pressure, expansion would occur during autoclaving, resulting in the destruction of the bricks and causing a decrease of strength. For another reason, higher forming pressures could make the forming machine suffer much more wear and tear than normal, such that the service time of the machinery is reduced dramatically.

\section{Practical engineering of EMSW autoclaved bricks}

To investigate the future applications of the technology for recycling EMSW, a production line making EMSW autoclaved bricks has been put into operation. This is the world's first production line on an industrial scale utilizing EMSW. The output of the line, which was built in Huifeng Manganese Co. Ltd. in Guizhou in June 2012, has reached 30 million bricks annually in the first stage of the project and 120 million bricks in the second stage. The detailed description of the practical engineering of EMSW is presented next, including the key processes, product performance, and environmental impact assessment. 
Table 5 Product performance of EMSW autoclaved bricks

\begin{tabular}{|c|c|c|c|c|c|c|}
\hline $\begin{array}{l}\text { Mix proportion } \\
\text { (EMSW }{ }^{\mathrm{a}} \text { :cement:C.A.:S.A.) }\end{array}$ & Size (mm) & $\begin{array}{l}\text { Compressive } \\
\text { strength }(\mathrm{MPa})\end{array}$ & $\begin{array}{l}\text { Bending } \\
\text { strength (MPa) }\end{array}$ & $\begin{array}{l}\text { Freeze-thaw } \\
\text { cycles passed }\end{array}$ & $\begin{array}{l}\text { Dry shrinkage } \\
(\mathrm{mm} / \mathrm{m})\end{array}$ & Color \\
\hline $30: 10: 5: 55$ & $240 \times 115 \times 53$ & 19.0 & 4.6 & 50 & 0.45 & Steel grey \\
\hline $35: 15: 8: 42$ & $240 \times 115 \times 53$ & 22.5 & 4.8 & 46 & 0.51 & Steel grey \\
\hline $40: 20: 10: 30$ & $240 \times 115 \times 53$ & 24.6 & 5.1 & 48 & 0.49 & Steel grey \\
\hline GB 11945 & $240 \times 115 \times 53$ & $\geq 15.0$ & $\geq 3.3$ & 15 & - & Consistency \\
\hline DIN V 106-2005 & $240 \times 115 \times 71$ & $\geq 16$ & $\geq 2.0$ & 50 & - & $\begin{array}{l}\text { Up to } \\
\text { purchaser }\end{array}$ \\
\hline ГОСТ $379-95^{\mathrm{c}}$ & $250 \times 125 \times 65$ & $\geq 17.5$ & $\geq 3.0$ & 25 & - & - \\
\hline ASTM C216-2012 & Up to purchaser & $\geq 17.2$ & - & Up to purchaser & $\begin{array}{l}\text { Water } \\
\text { absorption }\end{array}$ & $\begin{array}{l}\text { Up to } \\
\text { purchaser }\end{array}$ \\
\hline
\end{tabular}

${ }^{a}$ Referring to the pretreated EMSW; W:C kept at 0.4 , forming pressure $16 \mathrm{MPa}$

${ }^{\mathrm{b}}$ Referring to facing brick of grade 6 in the standard

${ }^{c}$ Referring to facing brick of grade 175 in the standard

${ }^{\mathrm{d}}$ Referring to facing brick of grade MW in the standard

\section{Product performance}

It is important that the performance of EMSW autoclaved bricks must satisfy the standard of autoclaved bricks. EMSW autoclaved bricks in different mix proportions after autoclaving and curing over a period of 28 days were sampled randomly after a continuous production of 7 days. About 100 bricks were collected for performance testing from each batch and the results are shown in Table 5.

As shown in Table 5, the compressive strength, bending strength, freeze-thaw cycles, dry shrinkage, and color of all the bricks of the three different mix proportions complied with the requirements of the GB11945-1999 Chinese standard. Thus, to acquire the good performance of the bricks, the appropriate mix proportion for production was determined as EMSW 30-40\%, cement 10-20\%, and aggregates $40-60 \%$. Using quicklime as the cementing material was unfavorable for making EMSW autoclaved bricks because the addition of quicklime was difficult to control and the strength was lower than that using the same amount of cement.

Key processes of the production line

To realize the industrial-scale production of EMSW autoclaved bricks, the process was designed based on the principles of simplicity, utility, and efficiency. Thus, there are four key processes of the production line: pretreatment, scaling and mixing, forming, and autoclaving. The pretreatment process takes charge of the stabilization of heavy metals in EMSW by mixing quicklime. After aging for 3-5 days, the EMSW and other materials are conveyed into the scaling and mixing process for preparing homogeneous raw mixtures with accurate proportions using a programmable logic controller (PLC). The raw mixtures are

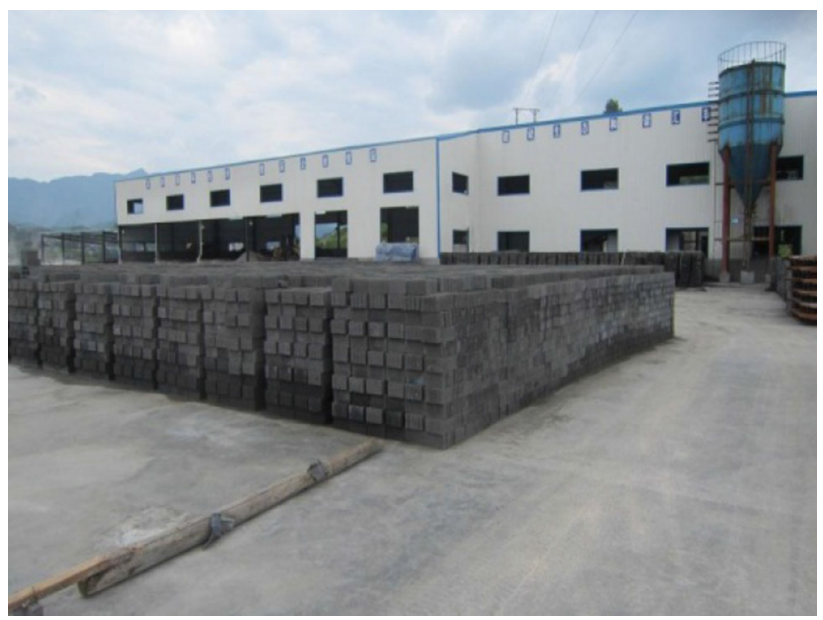

Fig. 18 Autoclaved bricks in stacks

transported into a collection bin to undergo the forming process with the ZY 360 forming device, which produces 60 bricks per minute. After curing in a warm house for $2-3 \mathrm{~h}$, the raw bricks are pulled into the autoclave for steam curing as part of the curing regime (2-6-3). Generally, a production line has to be equipped with two autoclaves: the steam from the dropping stage of the first autoclave can be used in the next autoclave for precuring, so as to save coal. After steaming, the bricks are stacked in the yard for 28 days (Fig. 18), until they can be put into use to build walls (Fig. 19).

Some pertinent aspects were noted in the actual production of EMSW autoclaved bricks; therefore, one should be wary of the following. (1) The quicklime addition in the pretreatment process should be $10-12 \%$ of the EMSW addition. Excessive quicklime will cause high $\mathrm{pH}$ of the EMSW and difficulty in slaking, resulting in serious fractures of the bricks. (2) The stirring time in the pretreatment 


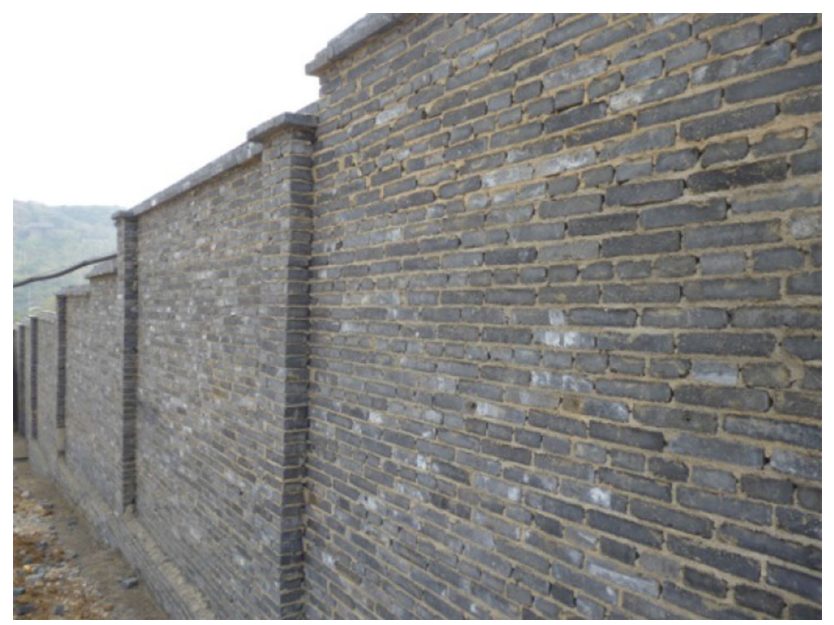

Fig. 19 A wall built using EMSW autoclaved bricks

process should not be too long, otherwise dispersed EMSW will agglomerate again and block the equipment. (3) Screening the raw mixture using a $2.5-\mathrm{mm}$ sieve before continuing into the hydraulic forming machine is required in order to protect the mold from hard particles. (4) The strict control of water addition is necessary; too much or too little water may decrease the strength of the bricks and cause cracks in the autoclave.

\section{Environmental risk assessment}

The mobilization of some heavy metals in the EMSW autoclaved bricks was investigated. The bricks were crushed and ground according to GB 5085.3-2007. Extraction solution with $\mathrm{pH} 3.20 \pm 0.05$ was used in this study. The waste samples were extracted at a liquid to solid ratio of 10 in capped polypropylene bottles in a rotary tumbler at $30 \pm 2 \mathrm{rpm}$ and $23 \pm 2{ }^{\circ} \mathrm{C}$ for $18 \pm 2 \mathrm{~h}$. The resulst are given in Table 3. The concentrations of the leachate of all the heavy metals were all below the threshold value of the standard. It may be deduced that the EMSW autoclaved bricks had low environmental risk. The evaluation of the long-term environmental risk requires modeling, depending on more tests.

The possible immobilization mechanisms of heavy metals could be chemical incorporation (surface complexation, precipitation, co-precipitation). In this case, heavy metals can be precipitated as hydroxides, carbonates, or silicates due to quicklime and cement. High $\mathrm{pH}$ may be the reason for immobilizing those heavy metals.

Implications of practical engineering

The establishment of the practical engineering of EMSW autoclaved bricks firstly addressed the issue of leaching in EMSW additions. The overall degree of stabilization on heavy metals was much improved by mixing additions and the amount of metals released into the environment was accepted by the regulation authority, since it can comply with the limits of the standards. The exposure on human beings and animals was much lower than that of untreated waste. Furthermore, the disposal of EMSW in large quantities was addressed, such that it is now possible to stabilize the heavy metals and completely blend them with other materials. Before this process, the plastic limit of the EMSW was far greater than coal-burning slag and steel slag; therefore, it was hard to spread evenly. In order to overcome this problem, the EMSW was crushed and scattered by a high-speed cutting device and it was then easy to integrate with additives having cementing materials.

\section{Conclusion}

The pretreatment of electrolytic manganese solid waste (EMSW) was necessary to stabilize manganese and other heavy metals, so that the test result of the toxicity characteristics of EMSW was within the threshold value and suitable for making bricks. Different cementing materials were added to bond EMSW and aggregates. Quicklime additions up to a threshold level did increase the compressive strength, but beyond which it posed a negative effect on the strength because the high $\mathrm{pH}$ would constrain the transformation of the $\mathrm{C}-\mathrm{S}-\mathrm{H}$ gel from strong alkalinity to weak. Cement as an ideal cementing material to create high strength with low addition could be used in industrialscale production. Quicklime and cement added simultaneously caused a lower strength than that of cement added alone, because the gypsum from EMSW and an alkali could cause deleterious effects, i.e., expansion or burst. With cement, as much as $60 \%$ of EMSW can be added in the bricks with good compressive and bending strengths, achieving 12.1 and $4.34 \mathrm{MPa}$, respectively. Appropriate elevation of the forming pressure can improve the strength of EMSW bricks.

For the production line of EMSW bricks, an appropriate mix proportion was determined as EMSW 30-40\%, cement $10-20 \%$, aggregates $40-60 \%, \mathrm{~W}: \mathrm{C}$ at 0.4 , forming pressure $16 \mathrm{MPa}$. In terms of the experience of practical production, the addition of quicklime and stirring of EMSW in pretreatment, screening before forming, and water addition should be noted. The concentration of heavy metals leaching from the EMSW autoclaved bricks, including that of manganese, was very low, which may have a low environmental risk. The evaluation of the longterm environmental risk requires more testing and leaching modeling of the contaminate solidified/stabilized in EMSW autoclaved bricks. 
Acknowledgments The authors appreciate the basic research fund of CRAES and Shandong Hengyuan Waste Utilization Co., Ltd. for the manufacturing device support.

\section{References}

1. Duan N, Dan Z-G, Song D-N (2011) Current status and directions for development of cleaner production technology of electrolytic manganese metal industry in China (in Chinese). J Environ Eng Tech 1:75-81

2. Duan N, Wang F, Zhou CB, Zhu C, Yu H (2010) Analysis of pollution materials generated from electrolytic manganese industries in China. Res Cons Recyc 54:506-511. doi:10.1016/j. resconrec.2009.10.007

3. Duan N, Dan ZG, Wang F, Pan CX, Zhou C, Jiang L (2011) Electrolytic manganese metal industry experience based China's new model for cleaner production promotion. J Clean Prod 19:2082-2087. doi:10.1016/j.jclepro.2011.06.024

4. Feng Y, Chen YX, Liu F, Bao X (2006) Studies on replacement of gypsum by manganese slag as retarder in cement manufacture (in Chinese). Mod Chem Ind 26:57-60

5. Lan J-Q (2005) How to exploit and use the "Dregs" produced from EMM-the rich selenium as fine fertilizer (in Chinese). China's Man Ind 23:27-30

6. Lan J-Q (2006) A test to corn production with fertilizer of Mndreg (in Chinese). China's Man Ind 24:43-45

7. Qiao D, Qian JS, Wang QZ, Dang Y, Zhang H, Zeng D (2010) Utilization of sulfate-rich solid wastes in rural road construction in the Three Gorges Reservoir. Res Cons Recyc 54:1368-1376. doi:10.1016/j.resconrec.2010.05.013

8. Xu FG (2001) Experimental research on application of Mn-slag to roadbed backfill (in Chinese). China's Man Ind 19:1-3

9. $\mathrm{Hu} \mathrm{CY}, \mathrm{Yu} \mathrm{HB}$ (2010) Preparation of ceramic tiles using electrolytic manganese residue (in Chinese). Bull Chinese Ceram Soc 29:112-116

10. Wang Y (2010) Research of utilizing electrolytic manganese residue for high pressure steam brick (in Chinese). Concrete 125-128. doi:10.3969/j.issn.1002-3550.2010.10.042

11. Peng T, Xu L, Chen H (2010) Preparation and characterization of high specific surface area $\mathrm{Mn}_{3} \mathrm{O}_{4}$ from electrolytic manganese residue. Cent Eur J Chem 8:1059-1068. doi:10.2478/s11532-0100081-4

12. Wang Y (2010) Pilot test on use of manganese slag and hilly sand in autoclaved brick (in Chinese). Brick Tile 8-11

13. ÖzverdI A, Erdem M (2010) Environmental risk assessment and stabilization/solidification of zinc extraction residue: $I$.
Environmental risk assessment. Hydrometallurgy 100:103-109. doi:10.1016/j.hydromet.2009.10.011

14. Peng DJ, Hu N, Peng QJ, Chen Y, Zhao W, Chen L (2006) Study on the leaching toxicity and safe disposal of manganese sulphate waste residue (in Chinese). Tech Equip Environ Pollut Control 7:100-102

15. Zhao F-Q, Zhao J, Liu H-J (2009) Autoclaved brick from lowsilicon tailings. Constr Build Mater 23:538-541. doi:10.1016/j. conbuildmat.2007.10.013

16. Cicek T, Tanriverdi M (2007) Lime based steam autoclaved fly ash bricks. Constr Build Mater 21:1295-1300. doi:10.1016/j. conbuildmat.2006.01.005

17. Oti JE, Kinuthia JM, Bai J (2009) Compressive strength and microstructural analysis of unfired clay masonry bricks. Eng Geol 109:230-240. doi:10.1016/j.enggeo.2009.08.010

18. Dermatas D, Dadachov M, Mirabito M, Meng X (2003) Strength development of solidified/stabilized organic waste and optimum treatment design. J Air Waste Man Assoc 53:1363-1372. doi:10. 1080/10473289.2003.10466302

19. Ubbriaco P, Tasselli F (1998) A study of the hydration of limepozzolan binders. J Therm Anal Calorim 52:1047-1054

20. Chen QY, Tyrer M, Hills CD, Yang XM, Carey P (2009) Immobilisation of heavy metal in cement-based solidification/ stabilisation: A review. Waste Manage (Oxford) 29:390-403. doi:10.1016/j.wasman.2008.01.019

21. Odler I, Zhang $\mathrm{H}$ (1996) Investigations on high $\mathrm{SO}_{3}$ portland clinkers and cements I. Clinker synthesis and cement preparation. Cem Concr Res 26:1307-1313. doi:10.1016/0008-8846(96) 00128-7

22. Scrivener KL, Damidot D, Famy C (1999) Possible mechanisms of expansion of concrete exposed to elevated temperatures during curing (also known as DEF) and implications for avoidance of field problems. Cem Concr Aggre 21:93-101. doi:10.1520/ CCA10513J

23. Glasser FP, Kindness A, Stronach SA (1999) Stability and solubility relationships in AFm phases: part I. Chloride, sulfate and hydroxide. Cem Concr Res 29:861-866

24. Ma ZC, Wang L, Ji GJ (2010) Effect of ettringite crystallization inhibitors on performance of sulphoaluminate cement. J Build Mater 13:395-397. doi:10.3969/j.issn.1007-9629.2010.03.025

25. Chen YF (2005) Study on autoclaving limes and brick using copper tailing. Dissertation, Hohai University

26. O'Farrell M, Wild S, Sabir BB (2001) Pore size distribution and compressive strength of waste clay brick mortar. Cem Concr Compos 23:81-91. doi:10.1016/S0958-9465(00)00070-6 